\title{
Symposium review: Challenges and opportunities for evaluating and using the genetic potential of dairy cattle in the new era of sensor data from automation*
}

\author{
N. Genglert \\ Gembloux Agro-Bio Tech, TERRA Research and Training Centre, University of Liège, 5030 Gembloux, Belgium
}

\section{ABSTRACT}

Sensor data from automation are becoming available on an increasingly large scale, and associated research is slowly starting to appear. This new era of sensor data from automation leads to many challenges but also new opportunities for assessing and maximizing the genetic potential of dairy cattle. The first challenge is data quality, because all uses of sensor data require careful data quality validation, potentially using external references. The second issue is data accessibility. Indeed, sensor data generated from automation are often designed to be available on-farm in a given system. However, to make these data useful - for genetic improvement for example - the data must also be made available offfarm. By nature, sensor data often are very complex and diverse; therefore, a data consolidation and integration layer is required. Moreover, the traits we want to select have to be defined precisely when generated from these raw data. This approach is obviously also beneficial to limit the challenge of extremely high data volumes generated by sensors. An additional challenge is that sensors will always be deployed in a context of herd management; therefore, any efforts to make them useful should focus on both breeding and management. However, this challenge also leads to opportunities to use genomic predictions based on these novel data for breeding and management. Access to relevant phenotypes is crucial for every genomic evaluation system. The automatic generation of training data, on both the phenotypic and genomic levels, is a major opportunity to access novel, precise, continuously updated, and relevant data. If the challenges of bidirectional data transfer between farms and external databases can be

Received September 17, 2018.

Accepted January 31, 2019.

*Presented as part of the Joint ADSA/Interbull Session: Phenotyping and Genetics in the New Era of Sensor Data from Automation at the ADSA Annual Meeting, Knoxville, Tennessee, June 2018.

†Corresponding author: nicolas.gengler@uliege.be solved, new opportunities for continuous genomic evaluations integrating genotypes and the most current local phenotypes can be expected to appear. Novel concepts such as federated learning may help to limit exchange of raw data and, therefore, data ownership issues, which is another important element limiting access to sensor data. Accurate genome-guided decision-making and genome-guided management of dairy cattle should be the ultimate way to add value to sensor data from automation. This could also be the major driving force to improve the cost-benefit relationship for sensorbased technologies, which is currently one of the major obstacles for large-scale use of available technologies. Key words: dairy cattle, management, breeding, genome-guided management

\section{INTRODUCTION}

Sensor data from automation are becoming available on an increasingly large scale (e.g., Bell and Tzimiropoulos, 2018), which leads to many challenges but also new opportunities in the management and breeding of dairy cows. Scientific interest, and therefore also literature on the topic, has been increasing recently: Scopus had, on average, less than one paper per year associating sensor, breeding, dairy, and cattle until 2016, but 3 papers in 2017 and 4 in 2018. These new developments will have a strong influence on how genetic potential of dairy cattle is evaluated, and on the use of these estimates of genetic potential to support sustainability of dairy production. However, a broad perspective is required because sustainability is not only linked to short- or long-term economics but also to environmental, genetic diversity, ethical, and social aspects (Olesen et al., 1999). All aspects need to be considered when assessing challenges and opportunities for evaluating and using the genetic potential of dairy cattle in the new era of sensor data from automation.

It is important to note that precision dairy tools allowing automatic collection of data in dairy cows are not completely new. Indeed, automatic milk meters assessing volume (e.g., Vogelauer, 1970) and automatic 
concentrate feeding stations (e.g., Ipema, 1980) have been around for some time, and ideas about integration into computerized data acquisition systems for dairy herd management date back at least to the 1980s (Speicher, 1981). As described by Rutten et al. (2013), tools for many traits have been developed over the years (e.g., major milk components and milk conductivity, daily $\mathrm{BW}$, rumen $\mathrm{pH}$, progesterone, behavioral patterns of feeding, rumination and activity, positioning, body condition scoring). An important step was the arrival of automated milking systems (AMS), which have become an important tool since preliminary studies in the 1980s (e.g., Rossing et al., 1985) and their first use on commercial farms in the early 1990s, leading to well over 25,000 AMS worldwide in the middle of the current decade (Barkema et al., 2015). It is generally considered that AMS associated with these new monitoring systems represent an excellent means to obtain potentially novel dairy cattle phenotypes (Bell and Tzimiropoulos, 2018). They also generate large quantities of this data, which leads to many other challenges.

In fact, sensor data from automation qualifies for at least four "Vs" associated with big data: Volumemany, often highly repeated records; Variety - coming from many different sensors; Veracity-posing serious issues of data integrity resulting from the quality of "sensors"; and finally Velocity - the need for rapid treatment of data from acquisition to advice (De Mauro et al., 2015). In a recent review, Wolfert et al. (2017) developed a conceptual framework applicable to "smart farming" to provide a systematic classification of issues and concepts for the analysis of this big data.

The goals of this paper are 2-fold. First, I will describe challenges and opportunities linked to the use of novel sensor data from automation for evaluating the genetic potential of dairy cattle and then I will review opportunities from potential novel uses of these estimates for selection and management. In this paper, I will focus on a holistic approach to describe this topic and on generating opportunities from genetics and genomics to improve cost-benefit ratios for farmers, an important element for the acquisition of sensor technologies but often only poorly considered during their design (Vannieuwenborg et al., 2017).

\section{CHALLENGES AND OPPORTUNITIES}

\section{Challenges: Data Quality and Data Validation}

A very important challenge in all processes based on data and data quality, where quality obviously needs a definition, is data validation. In a recent review, Wolfert et al. (2017) showed a series of operations on the raw data that may be necessary to ensure the quality of data. Data quality is a well-known issue and has been recognized for a long time as a limiting factor, especially in the field of genetic improvement of difficult-to-record traits as mastitis (Heringstad et al., 2000), claw health (Heringstad et al., 2018), and many other traits (EggerDanner et al., 2015). Automatic recording systems may also suffer from data quality issues at the basic sensor level (Løvendahl and Sørensen, 2016).

Directly linked to data quality is data validation: assuring the quality of data should be done by validating it. Guidance for novel sensor-based technologies can come from related technologies. Because of its long history of use in a sensitive context (milk payment), the example of mid-infrared (MIR) spectroscopy or spectrometry allows us to define data quality indicators. This is also currently a topic of intensive research for acquisition of novel traits (De Marchi et al., 2014) to exploit the richness of information in MIR-assessed fine milk composition (Gengler et al., 2016). In the use of infrared and especially MIR, dairy sector International Organization for Standardization and International Dairy Federation standards exist (e.g., Sjaunja, 2005) that define precision in terms of repeatability and reproducibility. The precise definitions of these terms are as follows. Repeatability means that results for the same samples determined at least in duplicate and on the same spectrometric instrument within a short time interval are identical; reproducibility implies that a replicated analysis is done on the same samples but under different conditions in time (e.g., days apart) and space (e.g., different instruments and laboratories). The concept of accuracy is based on how well values obtained by the evaluated method compare with "true" or reference values. A certain number of statistical parameters were defined to assess accuracy as detailed and used in the relevant literature (e.g., Sjaunja, 2005; Soyeurt et al., 2011). On-farm sensors are, by design, stand-alone; therefore, they need to have the means to be recalibrated toward external reference values or to be able to auto-adjust themselves. Efforts for standardization in agriculture are mostly channeled through the International Organization for Standardization, involving other relevant organizations such as the International Dairy Federation and the International Committee for Animal Recording (ICAR). The latter organization maintains a network of working groups and task forces that regularly update the ICAR Recording Guidelines (ICAR, 2017). The example of advanced milk meters can illustrate these efforts. Measuring milk quantity is quite reliable, and procedures to check and validate these devices are detailed in the ICAR Recording Guidelines (Section 11). However, obtaining reliable 
on-farm in-line milk components is another challenge and considered in a specific section of this guideline (Section 13). For technical and financial reasons, MIRbased technology currently has to be replaced by near infrared (NIR)-based technologies when used on-farm. As reported by Sjaunja (2005), NIR is less accurate than MIR, doubling the CV from $<1$ to $2 \%$. Several recent studies have tried to address the interest in NIRbased components estimation, even for novel traits as fatty acids (Nguyen et al., 2011). Others addressed the data quality that could be achieved compared with laboratory methods. A common conclusion (Kaniyamattam and De Vries, 2014; Hanuš et al., 2016) was that these methods gain by repeated sampling but also that recalibration toward reference values, which could be laboratory MIR values, is very important. Although the data quality and validation issues can be solved for milk component traits, this is less evident for novel types of sensors. A good example is $\mathrm{pH}$ boluses, which are technologically challenging (e.g., Schanzenbach et al., 2017), and many currently available tools lack long-term stability and are very expensive. It is still impossible to validate the results obtained, because it reference rumen $\mathrm{pH}$ measurements cannot be obtained in normal commercial settings.

In the animal data sector, ICAR is, through its guidelines, the most important reference body; its role is to ensure that we are measuring the same things and in the same way to generate data for use in breeding and management. The next question is to what extent the lack of data accuracy or precision, or both, affects the use of sensor data for breeding and management. As explained above, accuracy (also called "trueness" in metrology) is the difference between reference values and the average result from the sensor; the concept of precision relates to repeatability and reproducibility. In management applications, a lack of accuracy will lead to potentially consistently wrong decisions because decision support systems (e.g., for ketosis) are often working with thresholds (e.g., Iwersen et al., 2009; Macmillan et al., 2017). In breeding, as long as the trueness remains stable inside contemporary groups, estimations of genetic merit should be unbiased when appropriate fixed effects correcting for the mean are used. In management applications (i.e., ketosis detection), a lack of precision will negatively affect sensitivity (true positive rate) and specificity (true negative rate). In breeding, however, genetic models can be developed to describe repeated records and to discount for the potential lack of repeatability when estimating genetic animal effects. In genetic evaluations, it would be more problematic to have heterogeneity in the precision among data strata (e.g., instruments, laboratories) because it leads to heterogeneous variances in the data, which need to be addressed (i.e., by modeling the sources of heterogeneity as presented by Gengler et al., 2004). For fat and protein, which are currently estimated using MIR in routine DHI, an intercept and slope correction is applied after estimation using reference samples. For novel traits, this strategy might be difficult or impossible; therefore, alternative ideas are under development that standardize the data at an earlier stage (e.g., for MIR, see Grelet et al., 2015).

\section{Challenges: Data Consolidation and Modeling}

Most sensors are included in closed "ecosystems" that encompass the sensor, databases and computer programs, up to specific reporting tools, including specific computer terminals. We depend on the manufacturers of sensor-based technologies because the technical properties of sensors are usually not publicly known; therefore, we do not know when and how a sensor should be calibrated, how it drifts over time, or how much within-instrument variation is normal. One reason for this often-unsatisfactory situation is the underlying closed model. Except in research settings, raw data from the sensors are not available and farmers have access to preconfigured management traits. This limits the challenge of extremely high data volumes generated by sensors; however, it also limits the ability to consolidate and combine data outside of the sensor-specific ecosystems. We have to rely on the trait definitions developed by the manufacturer. As recognized recently by Bell and Tzimiropoulos (2018), sensor data from automation could become more relevant by combining data sources. The authors give the example of real-time prediction of nutrition requirements. Indeed, only by combining inputs for a large variety of variables - diet composition, nutrient intake and excretion, milk production and fine composition, BW, BCS, methane output, and knowledge of input and output prices - could such a system provide a holistic summary to advance feeding advice. Unfortunately, important efforts are needed to merge all of these types of data especially through DHI databases, the ORI-AUTOMATE initiative being one (Gengler et al., 2013), even if currently the implementations are only accessing AMS databases. The underlying strategy (i.e., access to databases) could be used for many sensor systems.

However, neither the acquisition nor the consolidation of sensor data will allow the generation of feedback for the farmer. A schematic representation is the flowchart given in Figure 1, summarizing how a "bioprocess" (the animal) generates a given "bioresponse," which is captured by a "sensor." Data from this sensor (and 


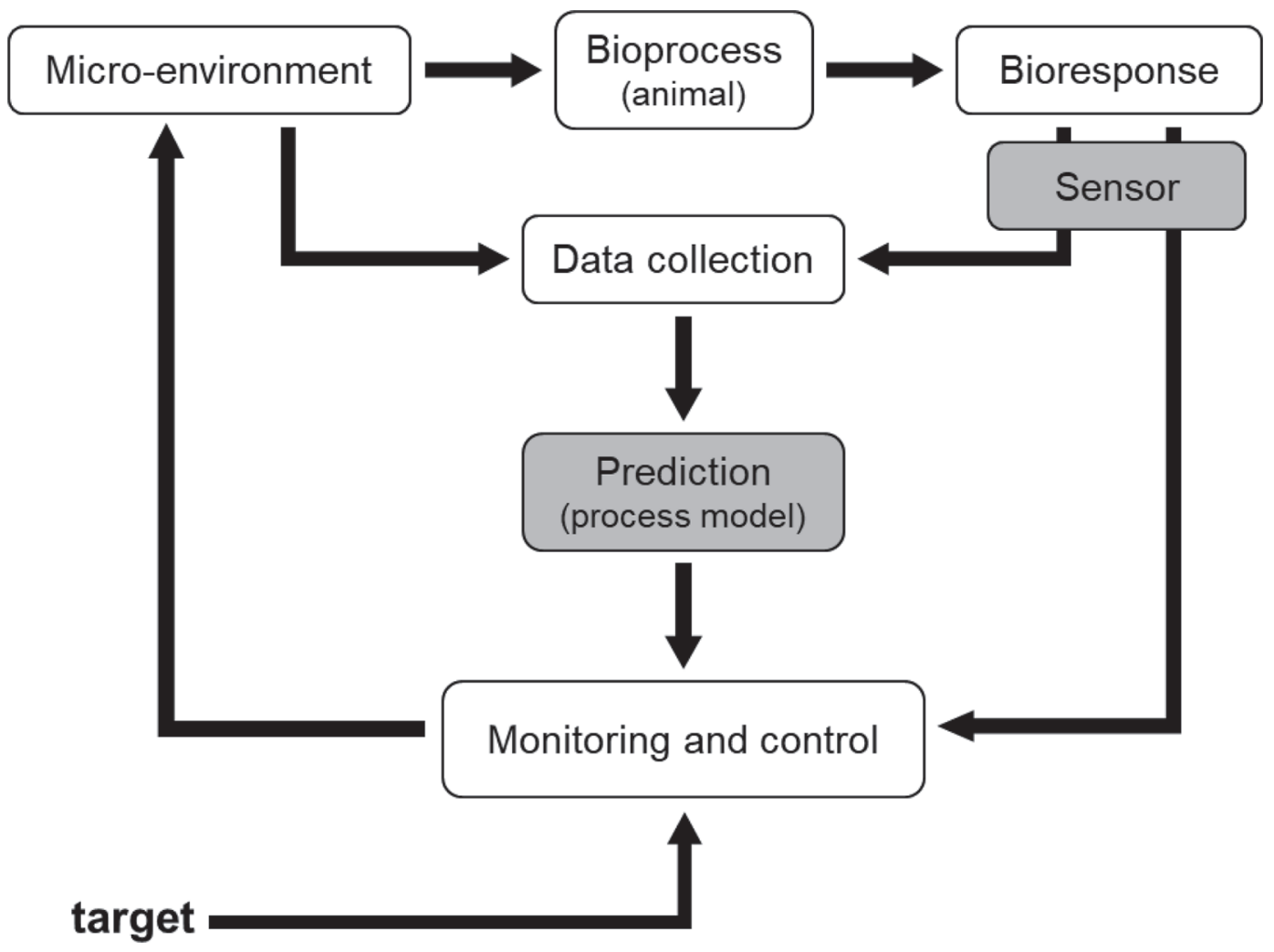

Figure 1. Typical setup of model-based process control. From Aerts et al. (2003) adapted by Gengler et al. (2013) with permission.

other sensors) are combined with environmental data, modeled to generate "predictions," which are compared in a monitoring and control process with observation to create feedback by using the collected data in an appropriate model to adjust the bioprocess. For dairy cattle, several research papers have presented strategies to do this type of modeling (Van Bebber et al., 1999; Mayeres et al., 2004; Bastin et al., 2009) in the context of repeated milk components measurements, but the basic concept can be applied in many situations. Common in all these methods is that after the prediction step through monitoring of the current situation, decisions are made (e.g., feeding) to affect the microenvironment that affects this bioprocess. Many refinements of these basic principles are possible (e.g., Jensen et al., 2016; Stygar et al., 2017) and often associated with dynamic linear programming or adopting process control strategies from industry (e.g., evolutionary operations, or EVOP, methods).

In a more integrative and holistic approach, Wolfert et al. (2017) structured the pathways from acquisition to the monitoring and control process. The authors identified different data cleaning and intelligent data processing techniques (Figure 2).

\section{Challenges: Use in Management and Breeding}

A hidden additional challenge is that sensors are almost always deployed in the context of (herd) management. This implies that the way they work is not necessarily optimized from a breeding perspective. In a breeding context, correct (i.e., unbiased) rankings of animals inside given contemporary groups showing no heterogeneity of variances across the data are more important than trueness or precision. In a breeding perspective, we can accept less precise values as long as the measurements are repeated on the same animal and across members of the same family. Automatic milking systems are large providers of novel data, directly or indirectly adding specific sensors, that correspond to this description. Several studies and reviews reported a large range from functional traits (Kramer et al., 2013; Egger-Danner et al., 2015) to environmental traits (Lassen et al., 2012), including behavioral traits (Adamczyk et al., 2013) such as milking frequency but also milk yield and milk composition (Løvendahl and Chagunda, 2011), udder health (Norberg, 2005), and fertility (Berglund, 2008). As many of these studies stress, the main challenge is to get these data into DHI 


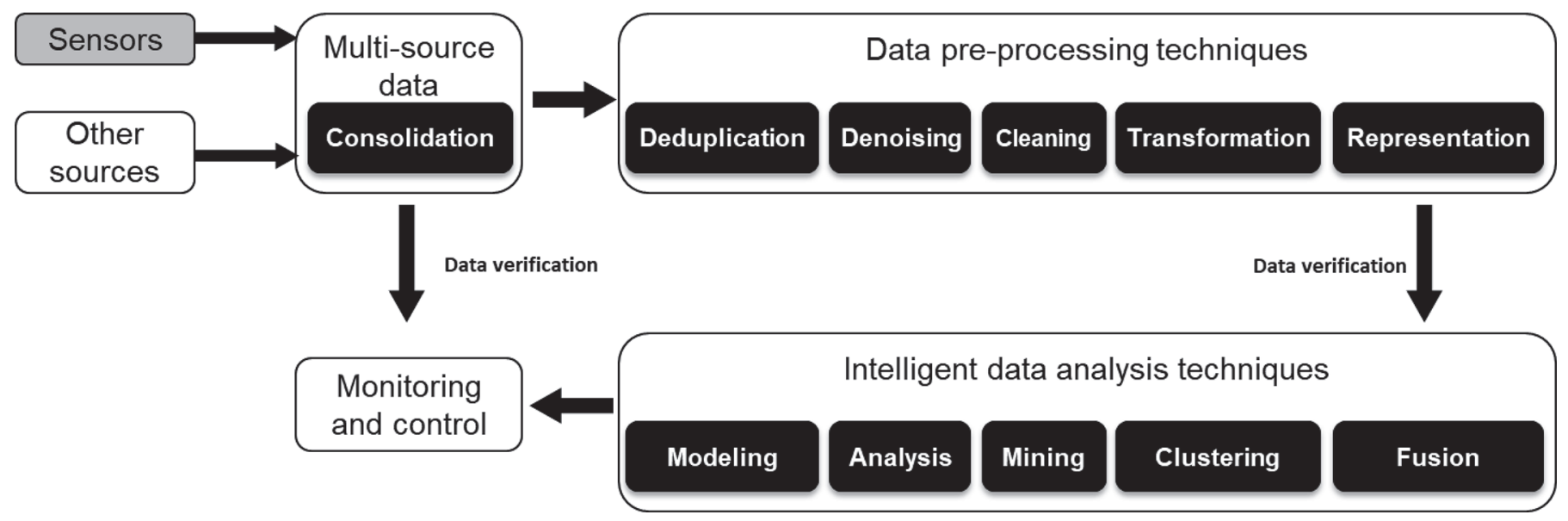

Figure 2. Flowchart adapted from Wolfert et al. (2017) citing Li et al. (2014).

and genetic evaluation system databases (Gengler et al., 2013).

\section{Challenges: Data Governance and Data Ownership}

A very practical issue that is often forgotten when it comes to using data from sensors through automation is what can be called "governance," which includes data ownership but also other issues such as privacy and security (Wolfert et al., 2017). I will not address the legal issues in depth here, especially because differences in legislation exist between countries and many issues are not yet settled law. However, many aspects and potential issues surround the legal considerations of sensor manufacturers, animal owners, data consolidators, database organizers, data users, and so on. In terms of technical "ecosystems," current business models often stand alone and are therefore "closed," limiting outside access to the data. Despite some legal uncertainties, some service providers have developed tools to access databases via on-farm computers. As explained before, this is technically challenging but also has potentially legal issues. A paradigm change to open business models will require a change of mentality toward an open collaborative approach because it brings clear advantages. This is not very different from the slow evolution toward open source in the software development field. Until then, it will remain very difficult to exchange, combine, and consolidate different data sources.

\section{Opportunities: Evaluating Animals and Creating Genetic Progress}

After addressing challenges, we can identify specific opportunities. Genetic evaluations need abundant and relevant data (Cole et al., 2012). However, this involves more than simply tapping into raw sensor data. Indeed, as very well described by Rutten et al. (2013), at least 4 levels can be distinguished: (1) technical (with raw data), (2) interpretation (leading to interpreted data), (3) integration of external information (leading to integrated data), and (4) decision-making, which is the least obvious level to be used as phenotypes. This specific multi-layer architecture opens new opportunities, as long as access to the relevant data is possible.

However, the real potential for genetic evaluations using sensor data from automation will be seen if we change the way genetic or genomic evaluations are conceived. In the context of genomic evaluations, it has become normal to consider a "continuous" computation of the genomic contributions for newly genotyped animals (e.g., Liu, 2014). Continuous evaluations (i.e., generally every few days or every week) are often in conflict with the amount of time required to perform all calculations on a national data set; therefore, it is common to use shortcuts to allow fast computation. Moreover, through sensor-based technologies, the phenotypic side of the evaluation could also become continuous. In fact, Wiggans and VanRaden (1993) have discussed this basic idea. It has to be stressed that continuous evaluation means that genetic information will be updated, but other aspects are involved, too (Cole et al., 2012). Functional bidirectional data exchange will be required, automatically transmitting from (e.g., phenotypic data) and to (e.g., evaluation results) the farm. Wiggans and VanRaden (1993) in particular, but also Cole et al. (2012), who insisted that processing time is important, suggested that some calculations might have to be made on-farm, which makes sense in our context given the extreme amounts of raw data that sensors may gen- 
erate and the post-processing that might be necessary. Unfortunately, even 25 yr after Wiggans and VanRaden (1993), current practice is far from these older ideas, despite their relevance in the genomic era. For example, SNP effects could be regularly updated and transferred to farms where sensors provided phenotypes would allow updating of genomic EBV on the female side. The definitive older concept of "predicted producing ability" (Wiggans et al., 1988) could be resuscitated as "genomically enhanced predicted producing ability" (GPPA). As GPPA would represent genomically enhanced expected differences between dairy cows in the future, it could be an important tool for management of dairy cows and not only for culling decisions. Currently, most on-farm computers, given their computing potential, are underused, and this dormant computing power could be very useful in integrating and treating local data.

Once data exchange issues are solved, we can go much further; that is, based on the concept of "federated learning," which is collaborative machine learning without centralized training data (McMahan and Ramage, 2017). Even if this concept is currently more used in smartphone applications, it might be very relevant in our field. Sensors could continuously generate "training" data, giving an opportunity for the federated system to access novel, precise, continuously updated, and relevant data. "Training" can mean many different things here, from data to updated phenotypic "sensor" algorithms to data going straight into federated genomic prediction models. Associated with the use of federated "deep" learning are many opportunities to change the way we are evaluating animals. Unfortunately, the current situation with the lack of fast internet in rural areas in many countries may be the real issue. Therefore, the innovations described above, which could help avoid the exchange of massive data by relying on the update of models (i.e., coefficients), may be the way to go. Moreover, a positive side effect of this type of approach is that the issues of data ownership may also no longer be as crucial.

The main objective of animal breeding is to create genetic progress. The so-called breeders' equation (Falconer and Mackay, 1996) can be used to describe the potential impact of sensor data. First, better and more accurate data recording should improve heritability, and the response of genetic progress should then be proportional for the selected trait. Also, sensors facilitate repeated measurements. Response on genetic progress will not be proportional because of the existing repeatability between repeated records, but the accuracy of evaluation will increase for selected traits. Moreover, a less direct influence of sensor data will be through the definition of novel traits correlated with index traits that contribute to the improvement of the breeding goal. Additional contributions to genetic progress could be generated by larger and better training data for genomics, leading to better genomic evaluations.

\section{Opportunities: Creating Added Value Using Genomics}

Many novel traits (e.g., disease-related traits) show medium to low heritability (Egger-Danner et al., 2015; Heringstad et al., 2018), in part because of the inaccuracy of data recording. Current, straightforward thinking is that sensor-based technologies will improve the accuracy of recording and therefore create opportunities for improved genetic progress for these traits. However, there might be another way to create added value using genomics. Indeed, even with sensor technologies, the directly observed phenotypes may not be the best data source to predict future problems. In these situations, the ultimate goal would be, as is already the case in human medicine (Aronson and Rehm, 2015), accurate genome-guided decision-making and genome-guided management of dairy cattle. Only a few examples of research in this field have been reported until recently (e.g., Weigel et al., 2017) but more research is ongoing. Advances in this alternative way to use genomics could be the driving force to improve the cost-benefit ratio for sensor-based technologies, which is currently one of the major obstacles for large-scale on-farm use of available technologies.

\section{CONCLUSIONS}

Access to relevant information is required for breeding and management of dairy cows. Sensors may allow definition of novel traits and access to these novel data. However, many challenges have to be addressed regarding sensor quality, data quality validation, the use of external training data, legal issues, and data accessibility in general. Indeed, sensor data generated from automation are often designed to be available onfarm within a closed system. To make these data useful (i.e., for genetic improvement), open systems should be developed so that the data are available off-farm and to facilitate a data consolidation and integration layer. Moreover, sensor data from automation create novel opportunities to generate genomic predictions for breeding and management. The automatic generation of training data is a major opportunity for continuous genomic evaluations integrating genotypes and the most current local phenotypes. Concepts such as federated learning may allow to limit the exchange of raw 
data and therefore also data ownership issues. Accurate genome-guided decision-making and management of dairy cattle should be the ultimate way to add value to sensor data. This could also be the major driving force to improve the cost-benefit ratio for sensor-based technologies, which is currently one of the major obstacles to their large-scale adoption.

\section{ACKNOWLEDGMENTS}

Nicolas Gengler, as a former senior research associate, acknowledges the support of the National Fund for Scientific Research (Brussels, Belgium). The author thanks the INTERREG IVB NWE program and the Ministry of Agriculture of the Walloon Region of Belgium (Service Public de Wallonie, Direction générale opérationnelle "Agriculture, Ressources naturelles et Environnement" - DGARNE) for their financial support for the OptiMIR project. The author also acknowledges the support of the European Commission under the Seventh Framework Program for the RobustMilk, GreenhouseMilk, and GplusE projects (grant agreements FP7-KBBE-211708, FP7-PEOPLEITN-2008-238562, and FP7-KBBE-613689). The content of the paper reflects only the view of the author; the European Community is not liable for any use that may be made of the information contained in this publication. Finally, the author thanks and acknowledges the important support of the Interbull Center, Uppsala, Sweden, for allowing him to attend the 2018 American Dairy Science Association (ADSA) annual meeting in Knoxville, Tennessee, where this symposium paper was presented.

\section{REFERENCES}

Adamczyk, K., J. Pokorska, J. Makulska, B. Earley, and M. Mazurek. 2013. Genetic analysis and evaluation of behavioural traits in cattle. Livest. Sci. 154:1-12. https://doi.org/10.1016/j.livsci.2013 .01 .016 .

Aerts, J.-M., C. M. Wathes, and D. Berckmans. 2003. Dynamic databased modelling of heat production and growth of broiler chickens: Development of an integrated management system. Biosyst. Eng. 84:257-266. https://doi.org/10.1016/S1537-5110(02)00285-4.

Aronson, S. J., and H. L. Rehm. 2015. Building the foundation for genomics in precision medicine. Nature 526:336-342. https://doi .org/10.1038/nature15816.

Barkema, H. W., M. A. G. von Keyserlingk, J. P. Kastelic, T. J. G. M. Lam, C. Luby, J.-P. Roy, S. J. LeBlanc, G. P. Keefe, and D. F. Kelton. 2015. Invited review: Changes in the dairy industry affecting dairy cattle health and welfare. J. Dairy Sci. 98:7426-7445. https://doi.org/10.3168/jds.2015-9377.

Bastin, C., L. Laloux, A. Gillon, F. Miglior, H. Soyeurt, H. Hammami, C. Bertozzi, and N. Gengler. 2009. Modeling milk urea of Walloon dairy cows in management perspectives. J. Dairy Sci. 92:35293540. https://doi.org/10.3168/jds.2008-1904.

Bell, M. J., and G. Tzimiropoulos. 2018. Novel monitoring systems to obtain dairy cattle phenotypes associated with sustainable production. Front. Sustain. Food Syst. 2:31. https://doi.org/10.3389/ fsufs.2018.00031.
Berglund, B. 2008. Genetic improvement of dairy cow reproductive performance. Reprod. Domest. Anim. 43:89-95. https://doi.org/ 10.1111/j.1439-0531.2008.01147.x.

Cole, J. B., S. Newman, F. Foertter, I. Aguilar, and M. Coffey. 2012. Breeding and Genetics Symposium: Really big data: Processing and analysis of very large data sets. J. Anim. Sci. 90:723-733. https://doi.org/10.2527/jas.2011-4584.

De Marchi, M., V. Toffanin, M. Cassandro, and M. Penasa. 2014. Invited review: Mid-infrared spectroscopy as phenotyping tool for milk traits. J. Dairy Sci. 97:1171-1186. https://doi.org/10.3168/ jds.2013-6799.

De Mauro, A., M. Greco, and M. Grimaldi. 2015. What is big data? A consensual definition and a review of key research topics. AIP Conf. Proc. 1644:97-104. https://doi.org/10.1063/1.4907823.

Egger-Danner, C., J.B. Cole, J.E. Pryce, N. Gengler, B. Heringstad, A. Bradley, and K.F. Stock. 2015. Invited review: Overview of new traits and phenotyping strategies in dairy cattle with a focus on functional traits. Animal 9:191-207. https://doi.org/10.1017/ S1751731114002614.

Falconer, D. S., and T. F. C. Mackay. 1996. Introduction to Quantitative Genetics. 4th ed. Longman, Essex UK.

Gengler, N., D. P. Berry, and C. Bastin. 2013. Use of automated systems for recording of direct and indirect data with special emphasis on the use of MIR milk spectra (OptiMIR project). ICAR Tech. Ser. 17:55-61.

Gengler, N., H. Soyeurt, F. Dehareng, C. Bastin, F. Colinet, H. Hammami, M.-L. Vanrobays, A. Lainé, S. Vanderick, C. Grelet, A. Vanlierde, E. Froidmont, and P. Dardenne. 2016. Capitalizing on fine milk composition for breeding and management of dairy cows. J. Dairy Sci. 99:4071-4079. https://doi.org/10.3168/jds.2015-10140.

Gengler, N., G. R. Wiggans, and A. Gillon. 2004. Estimated heterogeneity of phenotypic variance of test-day yield with a structural variance model. J. Dairy Sci. 87:1908-1916. https://doi.org/10 .3168/jds.S0022-0302(04)73349-4.

Grelet, C., J. A. Fernández Pierna, P. Dardenne, V. Baeten, and F. Dehareng. 2015. Standardization of milk mid-infrared spectra from a European dairy network. J. Dairy Sci. 98:2150-2160. https://doi .org/10.3168/jds.2014-8764.

Hanuš, O., L. Stádník, M. Klimešová, M. Tomáška, L. Hasoňová, D. Falta, J. Kučera, J. Kopecký, and R. Jedelská. 2016. The evaluation of real time milk analyse result reliability in the Czech Republic. Acta Univ. Agric. Silvic. Mendel. Brun. 64:1155-1166. https:/ /doi.org/10.11118/actaun201664041155.

Heringstad, B., C. Egger-Danner, N. Charfeddine, J. E. Pryce, K. F. Stock, J. Kofler, A. M. Sogstad, M. Holzhauer, A. Fiedler, K. Müller, P. Nielsen, G. Thomas, N. Gengler, G. de Jong, C. Ødegård, F. Malchiodi, F. Miglior, M. Alsaaod, and J. B. Cole. 2018. Invited review: Genetics and claw health: Opportunities to enhance claw health by genetic selection. J. Dairy Sci. 101:4801-4821. https:// doi.org/10.3168/jds.2017-13531.

Heringstad, B., G. Klemetsdal, and J. Ruane. 2000. Selection for mastitis resistance in dairy cattle: A review with focus on the situation in the Nordic countries. Livest. Prod. Sci. 64:95-106. https://doi .org/10.1016/S0301-6226(99)00128-1.

ICAR (International Committee of Animal Recording). 2017. ICAR Guidelines. Accessed Sep. 15, 2018. https://www.icar.org/index .php/icar-recording-guidelines/.

Ipema, A. H. 1980. Praktijkervaringen met geprogrammeerde krachtvoerverstrekking. Publikaties van het Instituut voor Mechanisatie, Arbeid en Gebouwen, Instituut voor Mechanisatie, Arbeid en Gebouwen, Wageningen, the Netherlands.

Iwersen, M., U. Falkenberg, R. Voigtsberger, D. Forderung, and W. Heuwieser. 2009. Evaluation of an electronic cowside test to detect subclinical ketosis in dairy cows. J. Dairy Sci. 92:2618-2624. https: //doi.org/10.3168/jds.2008-1795.

Jensen, D. B., H. Hogeveen, and A. De Vries. 2016. Bayesian integration of sensor information and a multivariate dynamic linear model for prediction of dairy cow mastitis. J. Dairy Sci. 99:7344-7361. https://doi.org/10.3168/jds.2015-10060.

Kaniyamattam, K., and A. De Vries. 2014. Agreement between milk fat, protein, and lactose observations collected from the Dairy 
Herd Improvement Association (DHIA) and a real-time milk analyzer. J. Dairy Sci. 97:2896-2908. https://doi.org/10.3168/jds .2013-7690

Kramer, M., M. Erbe, B. Bapst, A. Bieber, and H. Simianer. 2013. Estimation of genetic parameters for novel functional traits in Brown Swiss cattle. J. Dairy Sci. 96:5954-5964. https://doi.org/10.3168/ jds.2012-6236.

Lassen, J., P. Løvendahl, and J. Madsen. 2012. Accuracy of noninvasive breath methane measurements using Fourier transform infrared methods on individual cows. J. Dairy Sci. 95:890-898. https:/ /doi.org/10.3168/jds.2011-4544.

Li, X., S. Chen, and L. Guo. 2014. Technological innovation of agricultural information service in the age of big data. Zhongguo Nongye Ke-Ji Daobao 16:10-15.

Liu, Z. 2014. A continuous genomic evaluation system for German Holsteins. Interbull Bull. 48:100-104.

Løvendahl, P., and M. G. G. Chagunda. 2011. Covariance among milking frequency, milk yield, and milk composition from automatically milked cows. J. Dairy Sci. 94:5381-5392. https://doi.org/10 .3168/jds.2010-3589.

Løvendahl, P., and L. P. Sørensen. 2016. Frequently recorded sensor data may correctly provide health status of cows if data are handled carefully and errors are filtered away. Biotechnol. Agron. Soc. Environ. 20:3-12.

Macmillan, K., I. López Helguera, A. Behrouzi, M. Gobikrushanth, B. Hoff, and M. G. Colazo. 2017. Accuracy of a cow-side test for the diagnosis of hyperketonemia and hypoglycemia in lactating dairy cows. Res. Vet. Sci. 115:327-331. https://doi.org/10.1016/j.rvsc .2017.06.019.

Mayeres, P., J. Stoll, J. Bormann, R. Reents, and N. Gengler. 2004. Prediction of daily milk, fat, and protein production by a random regression test-day model. J. Dairy Sci. 87:1925-1933.

McMahan, B., and D. Ramage. 2017. Federated learning: Collaborative machine learning without centralized training data. Accessed July 3, 2018. https://ai.googleblog.com/2017/04/federated -learning-collaborative.html.

Nguyen, H., F. Dehareng, M. Hammida, V. Baeten, E. Froidmont, H. Soyeurt, A. Niemöeller, and P. Dardenne. 2011. Potential of near infrared spectroscopy for on-line analysis at the milking parlour using a fibre-optic probe presentation. NIR News 22:11-13.

Norberg, E. 2005. Electrical conductivity of milk as a phenotypic and genetic indicator of bovine mastitis: A review. Livest. Prod. Sci. 96:129-139. https://doi.org/10.1016/j.livprodsci.2004.12.014.

Olesen, I., B. Gjerde, and A. F. Groen. 1999. Methodology for deriving non-market trait values in animal breeding goals for sustainable production systems. Interbull Bull. 23:13-21.

Rossing, W., A. H. Ipema, and P. F. Veltman. 1985. Perspectieven voor het melken in een voerbox. Publikaties van het Instituut voor Mechanisatie, Arbeid en Gebouwen, Instituut voor Mechanisatie, Arbeid en Gebouwen, Wageningen, the Netherlands.

Rutten, C. J., A. G. J. Velthuis, W. Steeneveld, and H. Hogeveen. 2013. Invited review: Sensors to support health management on dairy farms. J. Dairy Sci. 96:1928-1952. https://doi.org/10.3168/ jds.2012-6107.

Schanzenbach, C., D. Ilver, J. Blomgren, C. Jonasson, C. Johansson, A. Krozer, L. Ye, and B.-O. Rustas. 2017. Preparation and characterisation of a sensing system for wireless $\mathrm{pH}$ measurements in vivo, in a rumen of a cow. Sens. Actuators B Chem. 242:637-644. https://doi.org/10.1016/j.snb.2016.11.089.

Sjaunja, L.-O. 2005. A review of spectroscopic methods and their suitability as analytical techniques for farm testing. Precis. Livest. Farming 5:25-32.

Soyeurt, H., F. Dehareng, N. Gengler, S. McParland, E. Wall, D. P. Berry, M. Coffey, and P. Dardenne. 2011. Mid-infrared prediction of bovine milk fatty acids across multiple breeds, production systems, and countries. J. Dairy Sci. 94:1657-1667. https://doi.org/ $10.3168 /$ jds.2010-3408.

Speicher, J. A. 1981. Computerized data acquisition systems for dairy herd management. J. Anim. Sci. 53:531-536. https://doi.org/10 $.2527 /$ jas $1981.532531 \mathrm{x}$.

Stygar, A. H., M. A. Krogh, T. Kristensen, S. Østergaard, and A. R. Kristensen. 2017. Multivariate dynamic linear models for estimating the effect of experimental interventions in an evolutionary operations setup in dairy herds. J. Dairy Sci. 100:5758-5773. https:/ /doi.org/10.3168/jds.2016-12251.

Van Bebber, J., N. Reinsch, W. Junge, and E. Kalm. 1999. Monitoring daily milk yields with a recursive test day repeatability model (Kalman filter). J. Dairy Sci. 82:2421-2429. https://doi.org/10 .3168/jds.S0022-0302(99)75493-7.

Vannieuwenborg, F., S. Verbrugge, and D. Colle. 2017. Designing and evaluating a smart cow monitoring system from a techno-economic perspective. Pages 1-8 in 2017 Internet of Things Business Models, Users, and Networks, Copenhagen, Denmark. Institute of Electrical and Electronics Engineers, New York, NY.

Vogelauer, R. 1970. Test report on the combined milk meter and milk flow indicator "Waikato". Milchwiss. Berichte 25:293-294.

Weigel, K. A., R. S. Pralle, H. Adams, K. Cho, C. Do, and H. M. White. 2017. Prediction of whole-genome risk for selection and management of hyperketonemia in Holstein dairy cattle. J. Anim. Breed. Genet. 134:275-285.

Wiggans, G. R., I. Misztal, and L. D. Van Vleck. 1988. Implementation of an animal model for genetic evaluation of dairy cattle in the United States. J. Dairy Sci. 71:54-69. https://doi.org/10.1016/ S0022-0302(88)79979-8.

Wiggans, G. R., and P. M. VanRaden. 1993. Flow of information for genetic evaluation of yield traits. Pages 20-30 in Symposium on Continuous Evaluation in Dairy Cattle, College Park, MD. University of Illinois, Urbana.

Wolfert, S., L. Ge, C. Verdouw, and M.-J. Bogaardt. 2017. Big data in smart farming - A review. Agric. Syst. 153:69-80. https://doi.org/ 10.1016/j.agsy.2017.01.023. 